University of Wollongong

Research Online

Faculty of Engineering and Information

Faculty of Engineering and Information

Sciences - Papers: Part B

Sciences

2017

\title{
A Consumer-Oriented Decision-Making Approach for Selecting the Cloud Storage Service: From PAPRIKA Perspective
}

\author{
Salim Al Isma'ili \\ University of Wollongong, szaai787@uowmail.edu.au \\ Mengxiang Li \\ Swinburne University of Technology, mli@uow.edu.au \\ Jun Shen \\ University of Wollongong, jshen@uow.edu.au \\ Qiang He \\ Swinburne University of Technology, qhe@swin.edu.au
}

Follow this and additional works at: https://ro.uow.edu.au/eispapers1

Part of the Engineering Commons, and the Science and Technology Studies Commons

Research Online is the open access institutional repository for the University of Wollongong. For further information contact the UOW Library: research-pubs@uow.edu.au 


\title{
A Consumer-Oriented Decision-Making Approach for Selecting the Cloud Storage Service: From PAPRIKA Perspective
}

\author{
Abstract \\ In recent years there is a growth in the number of companies that offers cloud storage solutions. From \\ user's perspectives, it is becoming a challenging task to choose which cloud storage to use and from \\ whom, based on user's needs. In this context, no framework can evaluate the decision criteria for \\ selection of cloud storage services. This paper proposes a solution to this problem by identifying the \\ cloud storage criteria and introduces the PAPRIKA approach for measuring the criteria of cloud storage \\ based on client's preference. This work demonstrated the applicability of the framework (decision model) \\ by testing it with eleven users of cloud storage services. The results showed that the model could help \\ users in making a more informative decision about cloud storage services.
}

\section{Keywords}

consumer, oriented, making, decision, selecting, perspective, cloud, storage, service, approach, paprika

\section{Disciplines}

Engineering | Science and Technology Studies

\section{Publication Details}

Al Isma'ili, S., Li, M., Shen, J. \& He, Q. (2017). A Consumer-Oriented Decision-Making Approach for Selecting the Cloud Storage Service: From PAPRIKA Perspective. Lecture Notes in Business Information Processing, 296 1-12. 


\title{
A Consumer-Oriented Decision-Making Approach for Selecting the Cloud Storage Service: From PAPRIKA Perspective
}

\author{
Salim Alismaili ${ }^{1}$ Mengxiang $\mathrm{Li}^{2}$, Jun Shen ${ }^{2}$, and Qiang $\mathrm{He}^{3}$ \\ ${ }^{1,2}$ School of Computing and Information Technology, University of Wollongong, Australia \\ ${ }^{1}$ szaai787@uowmail.edu.au; ${ }^{2}\{$ mli,jshen\}@uow.edu.au \\ ${ }^{3}$ School of Software and Electrical Engineering, Swinburne University of Technology, \\ Australia \\ ${ }^{3}$ qhe@swin.edu.au
}

\begin{abstract}
In recent years there is a growth in the number of companies that offers cloud storage solutions. From user's perspectives, it is becoming a challenging task to choose which cloud storage to use and from whom, based on user's needs. In this context, no framework can evaluate the decision criteria for selection of cloud storage services. This paper proposes a solution to this problem by identifying the cloud storage criteria and introduces the PAPRIKA approach for measuring the criteria of cloud storage based on client's preference. This work demonstrated the applicability of the framework (decision model) by testing it with eleven users of cloud storage services. The results showed that the model could help users in making a more informative decision about cloud storage services.
\end{abstract}

Keywords: Cloud storage, decision making, PAPRIKA approach.

\section{Introduction}

Cloud computing is a contemporary computing concept for conveying on-demand resources (e.g., infrastructure, platform, and software) to customers. The cloud computing services include: Software as a Service (SaaS), where customer access to applications that run on providers infrastructure; Platform as a Service (PaaS) where customer use provider's resources to develop applications or run custom applications; Infrastructure as a Service (IaaS) where customer use provider's environment provides services such as storage and networking infrastructure [1]. Our focus is the cloud storage which is a part of IaaS. Services providers usually offer IaaS storage with scalability option either up or down based on user's demand. Cloud storage permits users to store their data to an online server and access them remotely from anywhere. Data security and availability are some of the concerns from the user's perspective for the information warehoused in the cloud; some cloud storage providers solved these anxieties. For instance, Google Drive implemented a two-stage verification for ensuring additional security measure [2].

An informative decision making in the selection of the best cloud storage is crucial for any user even when the technologies offered for free. In some situations, it is even 
better in deciding on buying a service due to the supplementary features such as collaboration and higher security protections.

With the broad availability of cloud storage options in the market, it is becoming difficult for users to decide on the right option for them, even if the options are free of cost. Several parameters need to be considered such as cost, storage space, support, security, and reliability. Theses parameters in this context can be either quantitative such as cost and storage capacity or qualitative such as reliability and support. Currently, some users might decide on a certain cloud service based on other users review, other users might decide based on cost, another user may build his decision based on storage capacity. There is no wider framework which considers various parameters and rates them based on user preferences either individually or collectively for a group decision. In a global survey conducted in 2014 and involved 26,000 consumers indicated the importance of cloud storage to the majority of the participants irrespective of their gender group [3]. This implies the importance of cloud storage and the importance of this consumer segment. A forecast of personal cloud storage consumers worldwide estimated to reach to US \$ 1.8 billion people in 2017 [4] and it will continue in growing in the coming years. These data provide an indication of the size of this market and, therefore, the importance of this study. Despite the increased usage of cloud storage, there is no framework for assessing different cloud storages available in the market based on individual users' requirements. Therefore, we state our problem as it is difficult for consumers to make an informative decision on the appropriate cloud storage for their needs.

Quality measures assist in identifying which of the available cloud storage is the best and meets users' needs. Because of their significance, we selected the certain criteria that are based on ISO/IEC 94126 and a review of 25 websites of cloud services providers. ISO usability models do not cover all usability features [5]. Therefore, websites review was a necessary phase of this study. Some of the criteria were common and existed in both the ISO/IEC 94126 and from our review of the websites. The other criteria which will be evaluated and used to design our cloud storage decision model are storage space, support, upload and download speed, security measures, cost, and compatibility with different devices. Our decision model intends to help in providing a mechanism for ranking these criteria based on either individual or group preferences. The model is capable of generating each single user preference values. However, this paper presents only the results achieved by the panel (the case: University of Wollongong students) on their collective decision about their preference on the mentioned criteria.

\section{Related Work}

\subsection{Cloud Storage}

Allows users to store their data online and access them over the network from anywhere and through various computing interfaces. The hosting organisation which 
is the cloud storage provider installs a client application on a user's device. This application transfers any files that the users desires via the internet to the service provider then the file can be accessed and shared to other user's devices seamlessly and conveniently. Data can be synchronised to an auto update on all systems where the storage software is installed. Cloud storage have significant advantages in providing data accessibility, the reliability of services in comparing to the traditional storage solutions, secure storage, and disaster recovery. Also, the cloud storage cost is lower when compared with having the traditional storage setup with expensive hardware which enquiries management and maintained overheads. Cloud storage can be used to do various operations such as sharing files without the need to send email attachments, storing and accessing of data, additional backup and virtual collaboration with other users. Cloud storage providers are competing in delivering robust techniques for backing up and archiving of data in a secure, reliable, and practical environment. With the promised benefits, cloud storage has brought new concerns which were not there in the past computing environment such as security concerns and compliance issues. As a system cloud storage consists of three things: applications, platform, and the infrastructure. Cloud storage is offered in the three known types cloud computing: public, private, and hybrid. It is also delivered to individual users (personal). In general, cloud storage has several features such as resource pooling and multi-tenancy, scalability of the storage, Operational expenses (OPEX) costing model, sharing files, and collaboration [6]. Data transmitted to cloud storage in two ways either through web-based applications or web services application programming interfaces (APIs). Web-based applications are mainly applied for manual access to data, while APIs are used for managing automated processes [6]. Our focus in this paper is the evaluation of the personal cloud storage solutions.

\subsection{Cloud Storage Ranking}

Comparing and selection of cloud storage services have not been an easy task due to the wide availability of these services in different forms and with various suppliers. Sometimes the decision of the users is based on the volume of free storage space while other users might be more interested in the service that offers high security. It is believed that there are various factors can influence the embracing or use of cloud services might look in. In the next section, the paper will present seven factors which are found to be the most influential factors to users based on our tracking of user's reviews about the cloud storage services.

A study by Walker, Brisken [7] investigated investment option to lease cloud storage or to buy hard disk drives. Walker and colleagues presented a new modelling method based on comparing purchase cost versus leasing cost of cloud services and used empirical data. Ruiz-Alvarez and Humphrey [8] presented a mathematical model for allocation of datasets in cloud computing. Their model focused on the cost, performance, and the characteristics of cloud computing. Garg, Versteeg [9] used Analytical Hieratical Process (AHP) to rank cloud services based on customer's quality of services (QoS) requirements regarding criteria such as security and performance. According to our best knowledge, those are the few studies which could 
be relevant to this research; however, each study addressed a specific theme. It is believed that this work is the first attempt at providing an approach for ranking of cloud storage services for individual users. This work addresses cloud storages decision modelling and provides a decision approach based on PAPRIKA methodology taking into account individual user's requirements. This topic has not yet covered in the literature.

\subsection{Selection Criteria For Cloud Storage}

This work is a first attempt in this direction. The foundation of selecting the criteria (parameters) for this research is based on two aspects (a) International Standard Organisation ISO/IEC 9126 quality guidelines comprises a set of business based key performance indicators that are useful in evaluating services such as cloud storage, and (b) a review of twenty-five most popular cloud storage providers such as JustCloud, Zip Cloud, Google Drive, Microsoft OneDrive, IDrive, and Dropbox. The standard defined five characteristics (i) functionality, which explains the presence of multifunction's and their features; (ii) reliability, states the capability of software to sustain its performance level under defined conditions and time frame; (iii) usability, which is the extent of usage determination; ( $i v$ ) efficiency, which bears the association of the applied resources with the level of software performance; $(v)$ maintainability, which endures on the amount of effort consumed to make the intended alteration to the software; and (vi) portability, which is the degree of the transferability of the software from one platform to another [10].

There are still no definitions or measures of the identified attributes. The followings define these criteria:

Security: The degree of efficiency and protection of cloud storage services regarding access control, data privacy and confidentially. CSMIC [11] included various attributes that fall under this category including access control, physical and environmental security, and security management. Ensuring the security of transmission channels, methods, and the physical storage location is essential. Security requires using encryption, authorisation, and authentication measures [6].

Reliability: The capability of cloud storage provider to maintain its performance level without failure during a certain time and stated conditions. Cloud services providers should be able to provide a sufficient amount of assurance and demonstrate the acceptable extent of stability and resilience of their services to their clients.

Support: refer to the technical assistance provided by the cloud storage providers to its customers. Support can be provided using different means of communication.

Storage space: The amount of space available for storing data and it is measured in gigabytes.

Cost: Refers to the cost of cloud storage as per the specification offered. This might be the first concern appears in users' minds before they decide to adopt cloud storage. Using cloud storage could leverage savings on purchasing the traditional storage devices depending on the utilisation scope of each individual. Cloud storages offered at different plans and prices. 
Speed (uploads \& downloads): Refers to the response time. It is the unit of time takes to upload and download a unit of data. There is a variation of upload and download speed of the online storage services in the market.

Ease of use: Refers to the smoothness of using the cloud storage services in term of aspects such as data management, uploading and downloading files and folders, and accessibility. This criterion plays a vital role in the diffusion rate of cloud services. According to CSMIC [11], many factors such as accessibility, learnability, installability, operability, and transparency can fall in this category.

\section{Cloud Storage Decision Modelling}

The identified criteria and their specified levels based on the evaluation of the cloud storage providers and user's reviews and comments are mapped in Table 1 to design the decision model for this research.

The criteria level rankings start with lowest ranked to highest ranked as illustrated in Table 1. For example, for the cost criteria, the highest rank is identified to be affordable, and the lowest rank is when the cost of storage determined to be expensive. This paper aims to provide users with a framework to improve the decision-making process with more knowledgeable insights. The model will be tested with eleven cases to validate its functionality and applicability.

Table 1. Cloud storage decision model

\begin{tabular}{|c|c|c|c|}
\hline Criteria & Rank & Level & \multirow{18}{*}{$\begin{array}{l}0 \\
. \\
0 \\
0 \\
0 \\
0 \\
0 \\
0 \\
0 \\
0 \\
0 \\
0 \\
0 \\
0\end{array}$} \\
\hline \multirow[t]{2}{*}{ Storage space } & Lowest ranked & Sufficient & \\
\hline & Highest ranked & High & \\
\hline \multirow{2}{*}{$\begin{array}{l}\text { Upload \& download } \\
\text { speed }\end{array}$} & Lowest ranked & Reasonable & \\
\hline & Highest ranked & Fast & \\
\hline \multirow{3}{*}{$\begin{array}{l}\text { Compatibility with } \\
\text { PC, MAC, and } \\
\text { mobile devices }\end{array}$} & Lowest ranked & Only Compatible with either PC or & \\
\hline & & MAC & \\
\hline & Highest ranked & $\begin{array}{l}\text { Fully compatible with PC, MAC, } \\
\text { and mobile devices }\end{array}$ & \\
\hline \multirow[t]{2}{*}{ Reliability } & Lowest ranked & Reasonable (95\%) & \\
\hline & Highest ranked & High $(99 \%)$ & \\
\hline \multirow[t]{2}{*}{ Security measures } & Lowest ranked & Reasonable secured (98\% secured) & \\
\hline & Highest ranked & Highly secured (99.99\% secured) & \\
\hline \multirow[t]{2}{*}{ Ease of use } & Lowest ranked & Requires little knowledge & \\
\hline & Highest ranked & Easy to use & \\
\hline \multirow[t]{2}{*}{ Support } & Lowest ranked & Phone and email & \\
\hline & Highest ranked & $\begin{array}{l}\text { Phone, live chat, video tutorials, } \\
\text { and email }\end{array}$ & \\
\hline \multirow[t]{2}{*}{ Cost } & Lowest ranked & Expensive & \\
\hline & Highest ranked & Affordable & \\
\hline
\end{tabular}




\section{Methodology}

This paper proposing a ranking of cloud storage services using "Potentially All Pairwise RanKings of all possible Alternatives" (PAPRIKA) approach. The approach is the foundation for designing and developing a Multi-Criteria Decision Modelling (MCDM) for the cloud storage services ranking. Designing the model requires identifying the relevant criteria that have an impact on the usage of cloud storage services. Those criteria have been developed through examination of the user's reviews of the selection parameters available on twenty-five cloud storage providers. The criteria and their identified levels of preferences are the building blocks of the decision model for this research. The decision model was structured to reveal the relative importance (weights) of the criteria. This was achieved by the input of the participants revealing their preference on the criteria by responding to several questions which involved trade-offs between the criteria at the decisions step.

The evaluation of the preferences in the PAPRIKA method was achieved through the trade-off between all the criteria. The participants had three options to choose between every two compared criteria. These options are "pair one is better than pair two," "pair two is better than pair one," and "both pairs are equal" (Fig. 1).

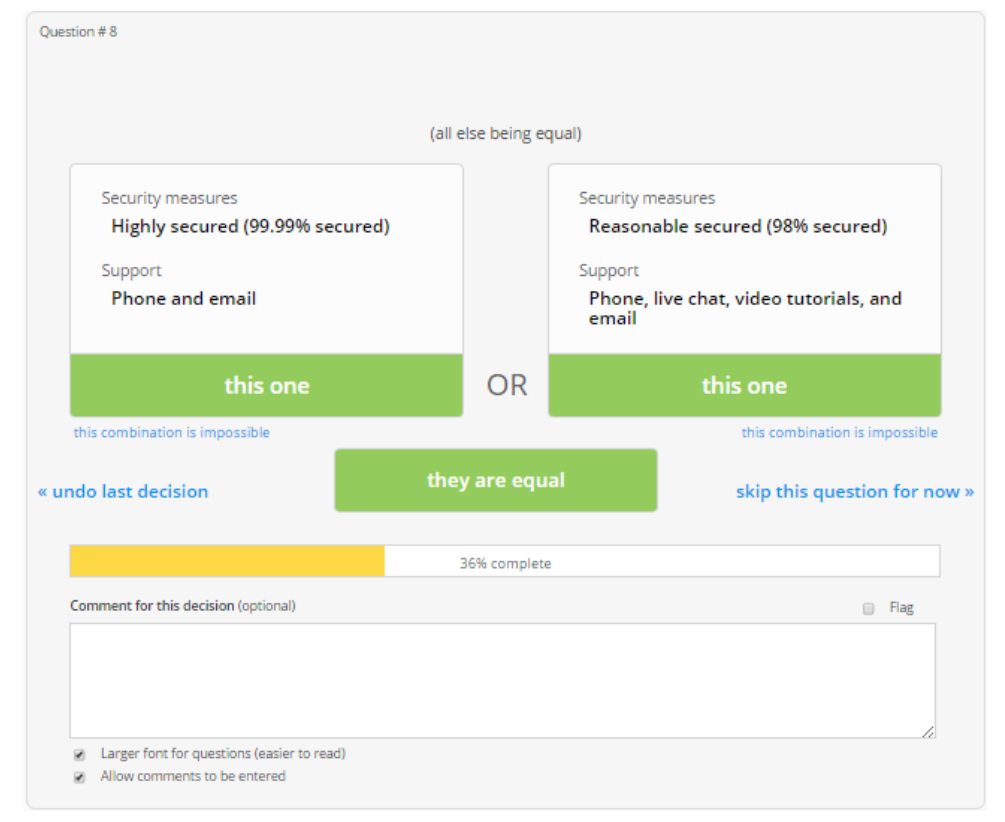

Fig. 1. Example of a pair-wise ranking trade-off question

The evaluated criteria for this study are qualitative in nature. The relative importance of each criterion is determined by the highest ranked of its preference level, and the total of all the highest preference levels are equal to $100 \%$ (data available upon request). 
PAPRIKA method is closer to human natural daily decision process as it is associated with comparing between two alternatives at a time. In this sense, it is more vigorous than AHP because AHP is based on 1-9 scaling system. PAPRIKA can theoretically rank any number of alternatives. By this way, PAPRIKA provides a more comfort in the final achieved decision. This research followed the following steps in modelling the cloud storage decision process:

1. Activity model: preparation of the model setup was established.

2. The activity design: for revealing the relative importance of the criteria.

3. Defining criteria: the criteria and their categories (levels) were implemented. The levels were also ranked based on the author's intuition that relies mainly on the review of the cloud storage providers and common sense.

4. Decisions: trading-off between criteria to reveal the preference value for each criterion for each survey participant.

5. Preference values and criterion ranking: the weight of importance of the criteria as determined by the participant as induvial or in a group.

PAPRIKA methodology was proposed to develop and test the cloud storage decision model for several considerations. First of all, its platform provides an easy to develop and deploy the decision model. Second, it reflects the natural human decision on a comparison between only two criteria at a time not like other methodology which evaluates several parameters and alternatives at once. Third, the survey development is cost efficient and clear. Fourth, the structure of the question is direct and efficient. Fifth, the approach is useful for subjective topics similar to this case as different people have different opinion and preferences in the features and type of cloud storage. Sixth, the method entails ranking of opposing substitutes through assessing all potential undominated pairs of criteria, arriving at more concrete results with a useful model [12]. Seventh, the method handles only two criteria to select among at a time, while SMART/SWING (Simple Multi-Attribute Rating Technique using Swing weights), outranking, and some CA (Conjoint Analysis) techniques use collective computations of the criteria to rank alternatives. This makes PAPRIKA resembling human intellect in making decisions because it is naturally easier to determine on a choice when there are fewer options for selection. In this sense, Forman and Selly [13] mentioned that accuracy in the scoring of alternatives depends on decision makers perception and their conception of the scoring scale. Eighth, PAPRIKA can incubate wider preference options than the majority of other alternative scoring methods [12], such as Discrete Choice Experiments/Conjoint Analysis (DCE/CA), Adaptive Conjoint Analysis (ACA), and the Analytical Hierarchy Process (AHP) [14]. For this paper, we propose PAPRIKA methodology; we argue that this method is proper for modelling the cloud storage.

\subsection{Survey}

The preference survey which was linked with the decision model was then distributed to the participants to reveal their collective decision on the ranking of the criteria. The survey was conducted online using PAPRIKA method through its interface named 1000Minds software [15]. Participants have the option to resume from their stopping point in the survey whenever they are ready. The update is occurring automatically 
with every newly completed survey for instant analysis. As this methodology provides the trade-off between only two criteria at a time, it, therefore, reduces the issues of participant's bias in answering the survey question without a careful reading of the questions. This bias issue is a common problem with other forms of questionnaire due to participants fatigue related to complexity and length of the surveys [16].

\subsection{Participants}

The participants of this study are students at the University of Wollongong/Australia who already used cloud storage. Their contact details were obtained randomly through a direct approach to various students in the campus. The students were from different disciplines. Data collected in July 2016. Following Macefield [17] guidelines in participates size, the responses from the eleven cases obtained in this study are sufficient to achieve the objective of testing the usefulness and applicability of the method (see Table 2).

Table 2. Participants progress report

\begin{tabular}{ll}
\hline Progress & Participants \\
\hline Excluded from activity & 0 \\
Email not sent yet (or no address) & 2 \\
Email sent, not started yet & 29 \\
Started (not finished yet) & 6 \\
Finished & 11 \\
\hline
\end{tabular}

\subsection{Cloud Storage Choice Modelling}

The cloud storage model was the foundation for running the preference surveys or the discrete choice experiments. The distribution activity of the survey was done through the model itself using the 1000 minds software platform. Within this model, two actions have been carried out: (I) discovering participants weight values of the criteria (ii) ranking the criteria.

\section{$5 \quad$ Results \& Discussion}

The paper presents the results of the criterion rankings for the eleven participants who completed $100 \%$ of the preference survey (preference values available with the authors upon request). 


\subsection{Criterion Rankings}

Table 3 demonstrates the ranking of the criteria for each of the participants with the group achieved median and mean values. It is understandable that every participant had a different opinion in their preference on ranking of the criteria due to the subjectivity of the topic.

Table 3. Criterion rankings

\begin{tabular}{|c|c|c|c|c|c|c|c|c|c|c|c|c|c|}
\hline & \multicolumn{13}{|c|}{ Participants } \\
\hline & $\begin{array}{l}n \\
n \\
n \\
n\end{array}$ & $\begin{array}{l}n \\
n \\
n \\
n\end{array}$ & 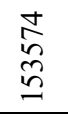 & 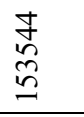 & $\begin{array}{l}n \\
n \\
n \\
n\end{array}$ & $\begin{array}{l}n \\
n \\
n \\
n \\
n\end{array}$ & $\begin{array}{l}n \\
\tilde{n} \\
n\end{array}$ & $\begin{array}{l}o \\
n \\
n \\
n \\
n\end{array}$ & $\begin{array}{l}i n \\
n \\
n \\
n\end{array}$ & $\begin{array}{l}\text { f } \\
\text { ñ } \\
n \\
n\end{array}$ & $\begin{array}{l}0 \\
1 \\
n \\
n \\
n\end{array}$ & 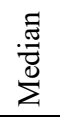 & $\sum_{\Sigma}^{\Xi \Xi}$ \\
\hline Storage space & $3 r d$ & $1 \mathrm{st}=$ & 4th & $2 \mathrm{nd}=$ & 2nd & 4 th & $1 \mathrm{st}$ & 2nd & 5 th & $1 \mathrm{st}$ & 7 th & 2.5 & 3.045 \\
\hline Ease of use & 5 th & 5 th & 6 th & $6 \mathrm{th}=$ & 4 th & 2 nd & $3 \mathrm{rd}$ & $3 \mathrm{rd}$ & $1 \mathrm{st}=$ & $3 \mathrm{rd}$ & $1 \mathrm{st}$ & 3 & 3.682 \\
\hline Support & 4 th & 6th & $1 \mathrm{st}$ & $2 \mathrm{nd}=$ & $1 \mathrm{st}$ & 7th & $4 \mathrm{th}=$ & 5 th & 4 th & 6th & 4 th & 4 & 4.136 \\
\hline $\begin{array}{l}\text { Upload/ } \\
\text { download } \\
\text { speed }\end{array}$ & 7th & $7 \mathrm{th}=$ & $3 \mathrm{rd}$ & $6 \mathrm{th}=$ & 5 th & $1 \mathrm{st}$ & $4 \mathrm{th}=$ & $1 \mathrm{st}$ & $6 \mathrm{th}=$ & 4 th & 2nd & 5 & 4.455 \\
\hline $\begin{array}{l}\text { Security } \\
\text { measures }\end{array}$ & $1 \mathrm{st}$ & $1 \mathrm{st}=$ & 2nd & $1 \mathrm{st}$ & 7 th & 8 th & $4 \mathrm{th}=$ & 7 th & $6 \mathrm{th}=$ & 8 th & $3 \mathrm{rd}$ & 5 & 4.591 \\
\hline$\underline{\text { Cost }}$ & 8th & $1 \mathrm{st}=$ & 5 th & $4 \mathrm{th}=$ & 6 th & 6th & 2nd & 8 th & $1 \mathrm{st}=$ & 2nd & 6th & 5 & 4.636 \\
\hline Reliability & 2nd & 4th & 7 th & $4 \mathrm{th}=$ & 8th & $3 \mathrm{rd}$ & 7th & 6th & 8th & 5 th & 8 th & 6 & 5.682 \\
\hline $\begin{array}{l}\text { Compatibility } \\
\text { with PC, } \\
\text { MAC, mobile } \\
\text { devices }\end{array}$ & 6 th & $7 \mathrm{th}=$ & 8th & $6 \mathrm{th}=$ & $3 \mathrm{rd}$ & 5 th & 8 th & 4 th & $3 \mathrm{rd}$ & 7 th & 5 th & 6 & 5.773 \\
\hline
\end{tabular}

\subsection{Criterion Weights}

Figure 2 presents the criteria weights and the mean value (i.e., the thicker black line). It is evident that the storage space is the most important criteria with a weight value of $16.4 \%$ and compatibility is the least valuable criteria with a weight value of $9.1 \%$. 


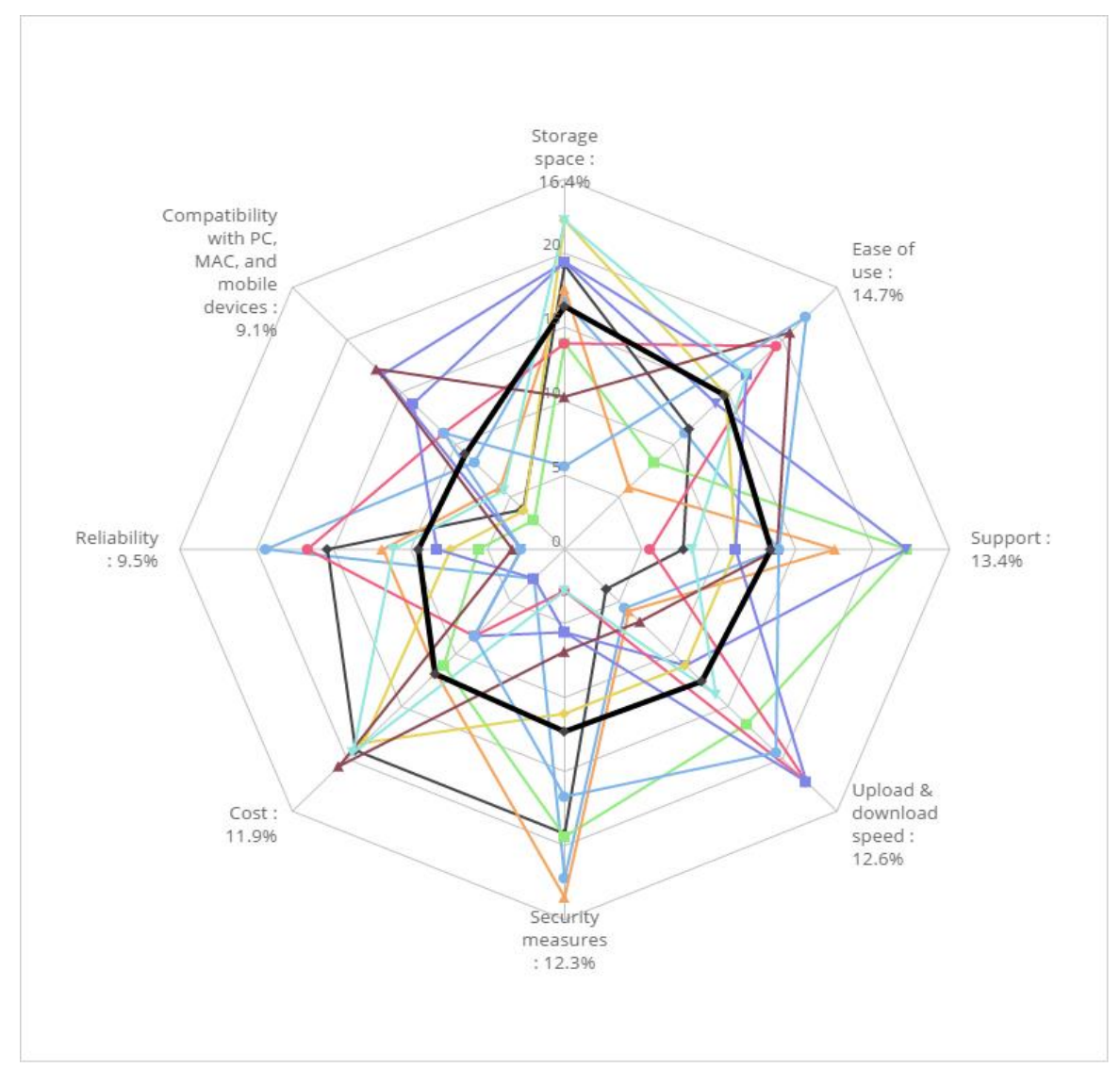

Fig. 2. Radar chart of criterion weights

\subsection{Relative Importance of Criteria (Mean Weights)}

Table 4 presents additional visualisation output to present an easy to read tabulation for users and decision makers for more informative decision. The table considers the marginal rate of substitution (ratio) of the column criterion for the row criterion. For example, (row 1, col2: 1.1) indicates that 'storage space' was more significant to participants for 1.1 than the 'ease of use' issues and (row 8, col6: 0.8) shows that 'compatibility' forms 0.8 of importance to the 'cost.' 
Table 4. Relative importance of the criteria (mean weights)

\begin{tabular}{|c|c|c|c|c|c|c|c|c|}
\hline & 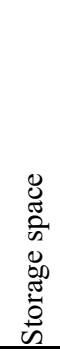 & 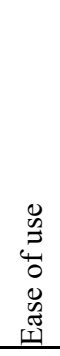 & 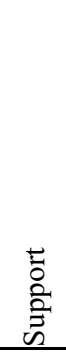 & 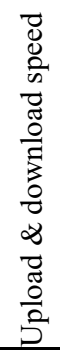 & 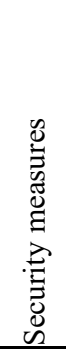 & 荿 & 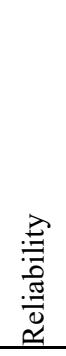 & 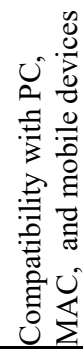 \\
\hline Storage space & & 1.1 & 1.2 & 1.3 & 1.3 & 1.4 & 1.7 & 1.8 \\
\hline Ease of use & 0.9 & & 1.1 & 1.2 & 1.2 & 1.2 & 1.5 & 1.6 \\
\hline Support & 0.8 & 0.9 & & 1.1 & 1.1 & 1.1 & 1.4 & 1.5 \\
\hline Upload \& download speed & 0.8 & 0.9 & 0.9 & & 1 & 1.1 & 1.3 & 1.4 \\
\hline Security measures & 0.8 & 0.8 & 0.9 & 1 & & 1 & 1.3 & 1.4 \\
\hline Cost & 0.7 & 0.8 & 0.9 & 0.9 & 1 & & 1.3 & 1.3 \\
\hline Reliability & 0.6 & 0.6 & 0.7 & 0.8 & 0.8 & 0.8 & & 1 \\
\hline $\begin{array}{l}\text { Compatibility with PC, } \\
\text { MAC, and mobile devices }\end{array}$ & 0.6 & 0.6 & 0.7 & 0.7 & 0.7 & 0.8 & 1 & \\
\hline
\end{tabular}

\subsection{Normalised Criterion Weights and Single Criterion Scores (Means)}

The criteria weights have been normalised summing to $100 \%$ (i.e. 1) and single criterion scores with a normalised scale from 0 to 100 points (see Table 5). In this table, the points system has been applied. The values show the significance of each criterion in comparison to the other criteria and their importance to the participants. Apparently, 'storage space' with a weight value of 0.164 has the highest level of significance among other criteria. The points system has been found to be easier to apply, vigorous, and more precise than the unassisted human judgments [18]. It is worth to mention that by changing the point values (i.e. single criterion scores), the ranking will change.

Table 5. Normalised criterion weights and single criterion scores (means)

\begin{tabular}{|c|c|c|c|}
\hline Criterion & $\begin{array}{l}\text { Criterion } \\
\text { weight }\end{array}$ & Level & $\begin{array}{l}\begin{array}{l}\text { Single } \\
\text { criterion }\end{array} \\
\end{array}$ \\
\hline & (sum to 1 ) & & $\begin{array}{l}\text { score } \\
(0-100)\end{array}$ \\
\hline \multirow{2}{*}{ Storage space } & \multirow{2}{*}{0.164} & Sufficient & 0 \\
\hline & & High & 100 \\
\hline
\end{tabular}




\begin{tabular}{l|lll}
\hline $\begin{array}{l}\text { Upload \& } \\
\text { download speed }\end{array}$ & 0.126 & $\begin{array}{l}\text { Reasonable } \\
\text { Fast }\end{array}$ & 0 \\
\hline $\begin{array}{l}\text { Compatibility with } \\
\text { PC, MAC, and } \\
\text { mobile devices }\end{array}$ & 0.091 & $\begin{array}{l}\text { Only Compatible with either PC or MAC } \\
\text { Fully compatible with PC, MAC, and } \\
\text { mobile devices } \\
\text { Reasonable (95\%) }\end{array}$ & 0 \\
\hline Reliability & 0.095 & $\begin{array}{l}\text { High (99\%) } \\
\text { Reasonable secured (98\% secured) }\end{array}$ & 100 \\
\hline Security measures & 0.123 & $\begin{array}{l}\text { Highly secured (99.99\% secured) } \\
\text { Requires little knowledge }\end{array}$ & 0 \\
\hline Ease of use & 0.147 & Easy to use & 100 \\
& & Phone and email & 0 \\
Support & 0.134 & Phone, live chat, video tutorials, and email & 100 \\
& & Expensive & 100 \\
Cost & 0.119 & Affordable & 0 \\
\hline
\end{tabular}

\section{Contribution, Limitations, and Future Research Direction}

This paper contributed in confirming the possibility to model a cloud storage decision-making process. The model was validated with real world cases. The research involved participants in the process of ranking criteria. The model forms a prototype which can be used by various stakeholders including cloud storage providers to gain additional insights to improve their services. Software developers to use the model and enhance it further to provide a comparison interface for potential users of cloud services. This framework is a first effort in this context; in the future work, we are aiming to improve the model by exploring other relevant quality parameters by incorporate them into the model. Investigating the insights of cloud storage from different stakeholders such as ICT experts and cloud storage providers themselves is a future research opportunity.

\section{Conclusion}

Cloud storage is increasingly becoming important for many people. Currently, there are many cloud storage services offered by different Cloud providers. One of the challenges that are faced by cloud consumers is how to select the best cloud storage services which can satisfy their needs. Therefore, this paper proposed an approach for calculating the Cloud storage preference values based on criteria relative importance (weights). This paper presented a first multi parameters framework in evaluating cloud storage preferences. 


\section{References}

1. Buyya, R., et al., Cloud computing and emerging IT platforms: Vision, hype, and reality for delivering computing as the 5th utility. Future Generation Computer Systems, 2009. 25(6): p. 599-616.

2. Trustradius. Cloud Storage Providers. 201517 March 2016]; Available from: https://www.trustradius.com/cloud-storage.

3. GfK. How essential is cloud storage for global consumers? 2015 [cited 10 November, 2016; Available from: https://www.statista.com/statistics/552738/worldwide-cloud-storagesurvey-importance-by-gender/.

4. Networking, C.V. Cisco Global Cloud Index: Forecast and Methodology, 2012-2017,(White Paper). 2013 [cited 13 November 2016; Available from:

http://www.cisco.com/c/dam/en/us/solutions/collateral/serviceprovider/global-cloud-index-gci/white-paper-c11-738085.pdf.

5. Abran, A., et al. Consolidating the ISO usability models. in Proceedings of 11th international software quality management conference. 2003.

6. Connor, D., et al., Cloud storage: Adoption, practice and deployment. An Outlook Report from Storage Strategies NOW, 2011.

7. Walker, E., W. Brisken, and J. Romney, To lease or not to lease from storage clouds. Computer, 2010. 43(4): p. 44-50.

8. Ruiz-Alvarez, A. and M. Humphrey. A model and decision procedure for data storage in cloud computing. in Cluster, Cloud and Grid Computing (CCGrid), 2012 12th IEEE/ACM International Symposium on. 2012. IEEE.

9. Garg, S.K., S. Versteeg, and R. Buyya, A framework for ranking of cloud computing services. Future Generation Computer Systems, 2013. 29(4): p. 1012-1023.

10. ISO, ISO/IEC 9126: Information Technology-Software Product Evaluation-Quality Characteristics and Guidelines for Their Use. 1991.

11. CSMIC, Service Measurement Index Framework Version 1.0 in USA 2014, Carnegie Mellon University Silicon Valley

12. Hansen, P. and F. Ombler, A new method for scoring additive multiattribute value models using pairwise rankings of alternatives. 
Journal of Multi-Criteria Decision Analysis, 2008. 15(3-4): p. 87107.

13. Forman, E.H. and M.A. Selly, Decision by objectives: how to convince others that you are right. 2001: World Scientific.

14. Saaty, T.L., How to make a decision: the analytic hierarchy process. European Journal of Operational Research, 1990. 48(1): p. 9-26.

15. Ombler, F. and P. Hansen. 1000Minds software. 2012.

16. De Vaus, D., Surveys in social research. 2013: Routledge.

17. Macefield, R., How to specify the participant group size for usability studies: a practitioner's guide. Journal of Usability Studies, 2009. 5(1): p. 34-45.

18. Hastie, R. and R.M. Dawes, Rational choice in an uncertain world: The psychology of judgment and decision making. 2010: Sage. 